\title{
A NOVA ORDEM PATRIARCAL: APONTAMENTO SOBRE A INSCRIÇÃO DAS MULHERES NA COLONIAL-MODERNIDADE
}

\author{
ELZAHRÃ MOHAMED RADWAN OMAR OSMAN ${ }^{1}$
}

\begin{abstract}
RESUMO: O debate contemporâneo sobre as colonialidades engendradas pela Conquista da América e pelos Imperialismos dos séculos XIX e XX possibilitou que o campo de estudos de gênero e feministas pudessem alargar suas reflexões teóricas para além do circunscrito projeto do movimento feminista branco euronortecentrado. $\mathrm{O}$ feminismo negro estadunidense, o feminismo chicano e, inclusive, feministas brasileiras como Lélia Gonzalez aportaram reflexões teóricas sobre a necessidade de se pensar a busca por igualdade de gênero por meio da justiça social, inscrevendo um feminismo radical a partir de concepções anticapitalistas, antirracistas e antipatriarcais. No entanto, devemos mais recentemente a teóricas como Oyèrónkë Oyěwùmí, María Lugones, Silvia Federici, Rita Segato e muitas outras novas compreensões sobre os efeitos de um sistema colonial de gênero, que fora gestado, inicialmente, no continente europeu, na passagem do feudalismo para o capitalismo, e cuja condição de existência reside nas duas barbáries coloniais. A partir do trabalho das teóricas acima referidas, este artigo intenta apresentar algumas reflexões sobre as características do patriarcado moderno, com o intuito de alargamos o olhar da teoria feminista contemporânea que busca abranger os outros 99 por cento.
\end{abstract}

PALAVRAS-CHAVE: Divisão sexual do trabalho; Família nuclear; Patriarcado moderno/colonial; Espaço público e privado; Feminismo não-branco.

\begin{abstract}
The contemporary debate about the colonialities engendered by the Conquest of America and the Imperialisms of the 19th and 20th centuries made it possible for the field of gender studies and feminist studies to extend their theoretical reflections beyond the circumscribed project of the Euronortecentred white feminist movement. American black feminism, Chican feminism and even Brazilian feminists such as Lélia González brought theoretical reflections to think about the search for gender equality through social justice, inscribing a radical feminism based on anti-capitalist, anti-racist and antipatriarchal modes of existence. However, we owe more recently to theorists such as Oyèrónkë Oyěwùmí, María Lugones, Silvia Federici, Rita Segato, and many others, new understandings about the effects of a gender system, which was initially elaborated in the European continent, in the passage from feudalism to capitalism, and whose condition of existence lies in the two colonial barbarities. Based on the work of the aforementioned theorists, this article attempts to present some reflections on the characteristics of this modern patriarchate in order to broaden the horizon of contemporary feminist theory that seeks to cover the other 99 percent.
\end{abstract}

KEYWORDS: Sexual division of labor; Nuclear family; Modern/colonial patriarchy; Public and private space; Non-white feminism.

\footnotetext{
${ }^{1}$ Pesquisadora-Tecnologista do Instituto Nacional de Estudos e Pesquisas Educacionais Anísio Teixeira vinculado ao Ministério da Educação. Doutoranda em Filosofia pela Universidade de Brasília (UnB). E-mail: assaddaka@gmail.com.
} 


\section{"A invenção das mulheres""}

A categoria universal "mulher" tem sido contestada desde, ao menos, o momento em que Simone Beauvoir pretendeu circunscrever a "história das mulheres" em seu $O$ Segundo Sexo (SAFIOTTI, 2015). Se deixarmos de reduzir a história universal àquela da metafísica ocidental e reorientarmos a escuta para as outras mulheres em um esforço distinto daquele de uma ontologia totalizante - se pretendermos destituir o outro da posição ontológica do não-ser -, será possível perceber modos de agência singulares ocorrendo em variados projetos históricos ${ }^{3}$; mas também que a história do ocidente foi recentemente construída como o padrão de referência acerca dos "processos civilizatórios", tanto aqueles relativos aos valores democráticos, quanto à secularização ou à justiça de gênero (GONZALEZ, 2011).

Tem sido comum, nas recentes tentativas de contar as histórias das mulheres, encontrar a descrição sobre lutas contemporâneas em períodos anteriores ou mesmo concomitantes à primeira onda feminista nos EUA e na Europa, muitas vezes com o intuito de legitimar ou mesmo provar a existência desses movimentos, ainda que não filiem-ne, necessariamente, à agenda dos assim chamados feminismos liberais (ARRUZA; BHATTACHARYA; FRASER, 2019). No entanto, a principal história deflagrada em contextos e meios variados é a de uma história única europeia como se pré-existente e independente dos seus "outros".

A título de exemplo, Ângela Davis, em já seu incontornável Mulheres, raça e classe (2016), por meio de estenuante pesquisa histórica, apresenta-nos uma instigante narrativa sobre o surgimento do movimento de mulheres brancas burguesas nos EUA, bem como a inspiração e apoios recebidos tanto dos homens dos movimentos abolicionistas (inclusive de mulheres negras) quanto do movimento das mulheres operárias. Ele se pautará pela busca por igualdade entre mulheres e homens por meio tanto do desvencilhamento da vida doméstica (instituição do matrimônio e condições sócio-políticas frustrantes) quanto da luta por acesso à educação, ao sufrágio e ao mercado de trabalho; mas será opaco diante das demandas trabalhistas levantadas pela difícil situação das mulheres brancas da classe trabalhadora, bem como das pautas abolicionistas e antirracistas das mulheres negras do norte e do sul dos EUA. Neste sentido, aponta Davis, não há que se falar em um feminismo negro a posteriori aos movimentos de mulheres brancas de classe média, mas em uma rede de influências e solidariedades mútuas,

\footnotetext{
2 Título emprestado do livro "The invention of women”, OYĚWÙMÍ, 1997.

3 "Projetos Históricos" é o termo utilizado por Rita Laura Segato em substituição à palavra cultura a fim de evitar caracterizações essencialistas relativas à cultura enquanto campo simbólico e identidade política. Projetos históricos colocam ênfase na mutabilidade histórica dos diversos coletivos, bem como na possibilidade inerente de deliberação interna em direção à resolução de conflitos morais.
} 
mesmo que não sempre presentes, e que conformaram a luta das mulheres brancas e negras contra o patriarcado, o sexismo e o racismo em períodos bastante próximos.

É bastante exemplificativo também o caso Sojourner Truth, mulher negra exescravizada que apresentou o seu espanto quando, na convenção de mulheres em Akron, Ohio, em 1851 (DAVIS, 2016), ouve argumentos relativos à fragilidade feminina. O discurso proferido por Truth é pródigo em demostrar que ali se falava sobre alguma mulher, mas não sobre todas. Ao perguntar à sua plateia "não sou eu uma mulher?", Truth traz à baila algo bastante discutido pela literatura que apresentaremos a seguir: o estatuto da mulher não branca foi, em contexto colonial, diferente do da mulher branca, pois aquela não precisou lutar para entrar no mercado de trabalho, não foi poupada dos esforços físicos a que pouparam "a mulher", foi domesticada para fins de reprodução social, apenas enquanto seus filhos eram roubados para a escravidão, não comungava dos atributos do sexo frágil, reduzido a um papel bastante circunscrito na família nuclear, e sim a outro tipo de "opressão".

Embora o feminismo negro não fosse um movimento separatista, dirá Davis (2016), a médio e longo prazo as demandas levantadas pelo "movimento de mulheres" brancas americanas não tinham radicalidade suficiente para incluir todas as demais mulheres (GONZALEZ, 2011). O que mais de uma vez apontará Davis é que a luta das mulheres americanas por mais espaço na sociedade capitalista liberal dar-se-á em um momento em que a chegada dos homens negros ao mercado de trabalho desestabilizaria certa ordem social já posta. Para elas, fica claro que não seria um novo "reposicionamento da base da pirâmide para cima" a solução para as desigualdades de gênero e raciais, mas um novo rearranjo social.

Para além do fato de hoje existir uma ampla recepção ao feminismo enquanto movimento analítico e político, inclusive aquele integrado às pautas radicais relativas à justiça social, a multiplicidade dos sistemas de opressão imbricados e nomeados por interseccionalidades pelas feministas negras, mas também por consubstancialidade pelas feministas marxistas com algumas especificidades (HIRATA, 2014), constituem, ainda hoje (como bem aponta também o Manifesto Feminismo para os 99\% (ARRUZA; BHATTACHARYA; FRASER, 2019)), um importante desafio metodológico e político para o feminismo enquanto uma luta transnacional que visa abolir o sexismo, mas também as hierarquias raciais, sociais, de gênero, geopolíticas e de imaginários (GONZALEZ, 2011), "productos de la modernidad occidental, del colonialismo y de la expansión capitalista global" (CURIEL, 2015, sem pg). 
A "história das mulheres" a ser apresentada neste artigo deslocará a categoria mulher, construída por um projeto epistêmico universal, ao longo do século XVI, a partir dos aportes oferecidos primeiramente por Silvia Federici (2017). Calibã e a Bruxa é reconhecidamente bem sucedido em demostrar como a categoria mulher constroe-se na Europa na passagem do feudalismo para o capitalismo; mais ainda, como o cercamento das relações sociais influenciará aquilo que se convencionou chamar de colonialidade de gênero.

Posteriormente, a partir do trabalho de Oyěwùmí (1997), apresentaremos a hipótese da autora relativamente à importação da categoria de gênero para a realidade da sociedade iorubá, seja por meio da implantação de uma cosmovisão ocidental, seja por meio de leituras antropológicas equivocadas. Maria Lugones (2008) vale-se da hipótese interpretativa de Aníbal Quijano sobre o "sexo, sus recursos y productos" a fim de demonstrar que o autor não questiona a universalidade da categoria de gênero utilizada na compreensão das relações sociais das comunidades indígenas na América. Rita Laura Segato (2016a), com o intuito de historicizar a categoria de gênero, teorizará sobre o estressamento de relações de gênero que instalaram um "patriarcado de alta intensidade" onde haveria um de "baixa intensidade". Sendo assim, podese dizer que a invenção das mulheres ocorrerá não apenas uma vez, mas por meio de histórias com imbricações mútuas que se conformaram em um determinado momento para, no seguinte, serem impostas para os outros povos coloniais como o padrão universalizante do gênero.

\section{A divisão sexual do trabalho na metrópole}

As pesquisas de Silvia Federici (2017) aportam dados históricos e análises bastante contundentes sobre a instituição do capitalismo, somando-se, assim, às prerrogativas principiológicas dos estudos sobre as colonialidades, pois ambas as perspectivas teóricas circusncrevem o surgimento do capitalismo articulado ao colonialismo, assim, às condições materiais e simbólicas que ensejaram a modernidade cristiano-ocidentalocêntrica, racista e epistemícida. O que Silvia Federici denominará de a "Grande Transformação" (2019, p. 42), a instituição do capitalismo, abarca fatos antevistos também pelo historiador francês Fernand Braudel em sua formulação sobre o longo século XVI (GROSFOGUEL, 2013): processos históricos ao longo dos anos de 1450 e 1650 que possibilitarão a implementação de um sistemamundo moderno capitalista, como denominado por Immanuel Wallerstein e pelos estudos sobre as colonialidades (GROSFOGUEL, 2013). Também Federici situa entre os séculos XVI e XVII os processos que ensejaram a grande caça às bruxas na Europa e na América colonial. Em contraposição a uma teleologia marxiana que enxergou na passagem do feudalismo para o 
capitalismo a possibilidade de emancipação pela aceleração dos processos de industrialização e por uma modernidade redentora relativamente aos padrões sociais feudais, os estudos sobre a colonialidade apontam para processos de perda de autonomia devido ao desmantelamento das terras comunais, empobrecimento em massa, pauperização das mulheres, cercamentos de terras e dos corpos, e esgarçamento do tecido comunitário. Como nos diz Federici,

\begin{abstract}
O capitalismo não poderia sequer ter decolado sem a "anexação da América" e sem o "sangue e suor" que durante dois séculos fluíram das plantations para a Europa. Devemos enfatizar essa questão na medida em que ela nos ajuda a perceber o quão essencial foi a escravidão para a história do capitalismo e porque, periódica mas sistematicamente, sempre que o sistema capitalista se vê ameaçado por uma grande crise econômica, a classe capitalista tem que pôr em marcha um processo de "acumulação primitiva", isto é, um processo de colonização e escravidão em grande escala, como o que testemunhamos atualmente. (FEDERICI, 2017, p. 207).
\end{abstract}

Federici não se contenta em apenas traçar um juízo de valor sobre a contraface do capital (colonização, escravidão, extração), seu discurso apresenta dados já bastante consagrados pela literatura histórica: "no século XVI, aproximadamente um milhão de escravos africanos e trabalhadores indígenas estavam produzindo mais-valia para a Espanha na América Colonial" (...) "Em 1600, o Brasil, sozinho, exportava o dobro de valor em açúcar que toda a lã exportada pela Inglaterra no mesmo ano" (...) "O ouro importado do Brasil reativou o comércio e a indústria na Europa. Eram importadas mais de 17.000 toneladas em 1640, que davam à classe capitalista uma vantagem excepcional quanto ao acesso a trabalhadores, mercadorias e terras" (FEDERICI, 2017, p. 206). Além de inúmeros outros exemplos sobre o acúmulo possibilitado pelo tráfico de escravos e pelo sistema de plantation que estabelece uma produção extrativista voltada ao mercado exterior ensejando a "construção de hierarquias raciais", a "divisão internacional do trabalho", que vimos no "uso posteiror da imigração" e nos processos de globalização com o intuito de "reduzir os custos do trabalho", e, por fim,

o que viajava com estas "exportações" não era apenas o sangue dos escravos, mas também as sementes de uma nova ciência da exploração e de uma nova divisão da classe trabalhadora, pela qual o trabalho assalariado, mais que oferecer uma alternativa ao trabalho escravo, foi transformado em dependendente da escravidão, enquanto mecanismo para ampliar a parte não remunerada do dia de trabalho assalariado - da mesma maneira que o trabalho feminino não remunerado (FEDERICI, 2017, p. 209).

Para Federici e para as demais teóricas que oferecem subsídios a sua pesquisa, como também para as autoras logo mais abordadas, aquilo que a autora chama de (2019, p. 55) "cercamento de conhecimento, de nosso corpo, de nossa relação com as outras pessoas e com a 
natureza" terá a mulher como sua principal vítima. Ao longo do livro Calibã e a Bruxa, Federici coletará dados sobre os dois séculos onde será possível averiguar o surgimento da categoria mulher, ou seja, do próprio sujeito do feminismo branco.

A partir do levantamento de dados sobre os cercamentos e a pobreza deles decorrente, Federici traça o estado de coisas onde as mulheres deixam um lugar de pertencimento a uma comunidade onde trabalhavam coletivamente com os homens em todos os ramos de produção necessários à manutenção do feudo (na terra, no lar e nas demais atividades econômicas) para um lugar de completa dependência ao que ela chamará de "Patriarcado do Salário" : a monetização da economia, a substituição do acesso à terra por um salário, a expulsão das mulheres do mercado de trabalho tornado paulatinamente sexista e disputado com os homens, a bruxificação de mulheres, geralmente velhas e pobres, detentoras do controle sobre a reprodução e muitas vezes organizadas em levantes contra a instauração da nova ordem, a constante perda de direitos (perdem o direito de realizar atividade econômica como femmes soles (FEDERICI, 2017, p. 199); fazer contratos, representar-se, e vários outros processos de infantilização legal), a dependência economica por meio do salário dos homens, mormente maridos, a criminalização do trabalho sexual, a caracterização como rebeldes e insubordinadas e, portanto, da necessidade de serem disciplinadas com vistas à reprodução social demandada pelo Estado e pelo Capital, vão deixando à mulher apenas duas opções: o casamento ou a morte.

A redefinição das tarefas produtivas e reprodutivas e consequente separação na transição para o capitalismo ensejarão a gênese do surgimento da função-trabalho do corpo proletariado por meio de uma nova divisão sexual do trabalho: aos homens o trabalho assalariado e a prerrogativa do controle sobre o trabalho não-assalariado, às mulheres a função-trabalho de reprodutoras e também a responsabilidade pela tarefas domésticas, agora desvalorizadas por não serem contabilizadas como parte do trabalho produtivo, uma vez que não remunerado.

A nova ordem patriarcal, então, é construída na modernidade ocidental a partir da feminilização e desvalorização da reprodução social. Para Federici, a categoria mulher não tem lastro no essencialismo, mas na feminilidade enquanto função-trabalho, "oculta sob o disfarce de um destino biológico", como se ela tivesse vocação natural para o trabalho reprodutivo. A divisão sexual do trabalho é, portanto, a chave para a compreensão do domínio masculino, do controle da sexualidade feminina e da maternidade compulsória e disciplinada, "degradada à condição de trabalho forçado".

Assim, a redução do trabalho feminino ao trabalho doméstico ensejou o próprio surgimento da "mulher" na medida em que o lar tornou-se o seu "lugar" onde as relações 
sociais cercadas se constituíram. A mulher (mãe, esposa, filha, viúva) substitui a terra comunal perdida sob a posse de um homem que detinha direitos sobre ela, é um recurso natural que lhe dá diversos frutos, todos relacionados à reprodução da vida, função sine qua non o capitalismo não existiria.

É preciso nos referirmos ao trabalho doméstico (FEDERICI, 2013, p. 38) no seio insurgente da família nuclear enquanto trabalho feminino. Este inclui não apenas lavar, passar, cozinhar, mas também cuidados afetivos e físicos com os membros da família (homens e crianças); na medida em que inclui a gestão do lar, o serviço sexual, a docilidade, a subserviência a um chefe da família, ao exercício de um determinado papel da mulher "esposa ideal, passiva, obediente, parcimoniosa, casta, de poucas palavras e sempre ocupada com suas tarefas", caracterizações surgidas por meio de uma redefinição ideológica das relações de gênero. As mulheres pós caça às bruxas deixam de ser paulatinamente retratadas como "seres selvagens, débeis, rebeldes, insubordinadas", para, já no século XVIII, tornaram-se "seres passivos, assexuados, mais obedientes e morais que os homens, capazes de exercer uma influência positiva sobre eles" (FEDERICI, 2017, p. 205). São suas características psicológicas (a psique e a personalidade feminina) e suas necessidades internas que a predispõem para isso. É uma característica natural, inevitável e a realiza plenamente, pois é um ato de amor, por meio do qual "torna-se uma mulher de verdade" (FEDERICI, 2013, p. 38).

\section{Há um sistema colonial de gênero?}

A historicização da categoria de gênero "mulher" pela filósofa e historiadora Silvia Federici, bem como as formulações teóricas de autoras que refletiram sobre a existência de padrões de gênero exógenos aos projetos históricos anteriores à colonização, nos auxiliam a delinear o desenvolvimento da instauração de hierarquias sociais, de raça e de gênero por meio do continum metrópole-colônia (GONZALEZ, 2011).

No entanto, algumas das principais dissensões relativamente a algumas das características de um Sistema Colonial de gênero serão formuladas pela antropóloga Rita Laura Segato. A autora posiciona-se em um termo médio entre uma visão eurocêntrica sobre a existência irrefutável da categoria de gênero e a ideia de que o gênero não fosse de modo algum um elemento importante da organização social. No entanto, em um de seus textos mais recentes, ela também se filia às que vêem na suposta "estructura de tiempo larguísimo" a "discontinuidad del patriarcado a partir de la experiencia de la conquista y la colonización” (SEGATO, 2016b, p. 165). 
As reflexões teóricas de Segato, advindas do trabalho de campo em antropologia, mas também da literatura etnográfica, são apontamentos sobre a existência das relações de gênero nas sociedades pré-coloniais, cujas hierarquias não se constituíam em letalidade às mulheres na proporção a que assistimos na modernidade. Ainda assim, os apontamentos referentes a um estressamento das hierarquias pré-existentes (ou instaladas) coadunam-se com o que Lugones (2008) e Oyěwùmí (1997) informam em seus escritos: a categoria mulher não é universal (embora o patriarcado seja para Segato) e as relações de gênero na modernidade são uma inflexão na história das relações sociais contemporâneas: "como argumentei, se é possível dizer que sempre houve hierarquia e relações de poder e prestígio desiguais, com a intervenção colonial estatal e a imposição da ordem da colonial/modernidade, essa distância opressiva se agrava e amplifica" (SEGATO, 2012, p. 128).

A despeito da existência de dissenções, é notável, entre as autoras, a afluência das implicações sobre os efeitos da colonialidade de gênero: a divisão sexual do trabalho, a privatização das relações de gênero por meio da nuclearização familiar, "o controle sobre o sexo, seus recuros e produtos", a "minorização" das questões femininas, o rebaixamento do espaço privado e a exaltação do espaço público, a universalização e surgimento do outro feminino, racializado e marginalizado, a instalação de uma hierarquia "femi-geno-cida" (SEGATO, 2016b), o empobrecimento e a subjugação de metade da humanidade, o fim dos laços com a terra e com a comunidade, a bruxificação (Silvia Federici), e a "guerra às mulheres" (Rita Segato).

Oyěwùmí é a autora que melhor exemplifica o desconforto com a categoria de gênero como utilizada nos estudos femininistas e aplicada por etnografias brancas sobre o povo iorubá do nordeste da Nigéria. O que surpreende, no entanto, é a caracterização que faz do gênero, pois, inadvertidamente, o modo como ela o percebe nos estudos feministas é não mais do que a categoria que Federici vê construída na modernidade:

\footnotetext{
1) As categorias de gênero são universais e atemporais e estão presentes em todas as sociedades, em todos os tempos. Muitas vezes, a ideia é expressa em um tom bíblico, como se sugerisse que "no princípio era o gênero". 2) O gênero é um princípio organizador fundamental em todas as sociedades e, portanto, é sempre proeminente. Em cada sociedade, o gênero está em todo lugar; 3) Há uma categoria essencial e universal "mulher", que é caracterizada pela uniformidade social de seus membros. 4) A subordinação das mulheres é universal e 5) A Categoria "mulher" é pré-cultural, fixada no tempo histórico e no espaço cultural, em antítese a uma outra categoria fixada: "homem" (OYĚWÙMÍ, 1997, p. 7).
}

Para Oyěwùmí, parece óbvia a fixação dos estudos feministas brancos à categoria de gênero, visto que nestas sociedades o núcleo de análise é a família nuclear, "generificada por 
excelência", onde a categoria mulher subsume-se à de esposa, e obviamente à de mãe, estando submetida junto com a prole à figura de autoridade masculina da tríade - o marido como o representante do "privilégio do gênero masculino como uma parte essencial do ethos europeu" (OYĚWÙMÍ, 2004, p. 1). Assim, uma vez que classe e raça não são características que se interpenetram na família nuclear o feminismo branco seria consequentemente cego a tais interseccionalidades. Contrariamente,

\begin{abstract}
A família Iorubá tradicional pode ser descrita como uma família não-generificada. É não-generificada porque papéis de parentesco e categorias não são diferenciados por gênero. Então, significativamente, os centros de poder dentro da família são difusos e não são especificados pelo gênero. Porque o princípio organizador fundamental no seio da família é antiguidade baseada na idade relativa, e não de gênero, as categorias de parentesco codificam antiguidade, e não gênero (OYĚWÙMÍ, 2004, p. 6.)
\end{abstract}

Ter a família nuclear como uma das categorias mais básicas de análise não é um problema por si só. Como pontuará Federici (2017, p. 31): “as atividades associadas à reprodução seguem sendo um terreno de luta fundamental para as mulheres (...) e um nexo com a história das bruxas". A problemática que se levanta para Oyěwùmí e orienta a argumentação dos discursos aqui analisados refere-se ao uso e abuso de uma categoria que se apresenta como se fosse atemporal e universal.

A partir de ampla consulta a etnografias sobre a América pré-hispânica (e também inspirada em Oyěwùmí), María Lugones (2008) afirmará a existência de modos outros de organização social que não se reproduziam por meio de uma hierarquia de gênero: "el género no fue entendido ante todo en términos biológicos. La mayoría de los individuos encajaban dentro de los roles de género tribales 'en base a propensión, inclinación y temperamento' (LUGONES, 2008, p. 90).

Assim, o lado visível/claro do Sistema colonial de gênero (LUGONES, 2008) diz-se por meio de todos os subterfúgios necessários para a consolidação do gênero resumido em "dimorfismo sexual hiperbiologizado", "organização patriarcal das relações sociais" e "heterossexualidade compulsória", sem o qual a categoria mulher não poderia ter sido importada, ainda que não se tenha herdado o status das mulheres brancas. O lado escuro/invisível da organização colonial/moderna do gênero (LUGONES, 2008) é o subproduto do processo de generificação, racialização, redução do gênero ao privado, controle do "sexo, seus recursos e produtos", causados por mudanças na estrutura social impostas pelo sistema capitalista/colonial, pela "desintegración de las relaciones comunales e igualitarias, del pensamiento ritual, de la autoridad y el proceso colectivo de toma das decisões e das 
economias" (LUGONES, 2008, p. 93). E apenas se desvelam em contraste com a compreensão da organização social do sexo pré-colonial "en todos los ámbitos de la existencia incluyendo el saber y las prácticas rituales, la economia, la cosmología, las decisiones del gobierno interno y externo de la comunidad" (LUGONES, 2008, p. 93).

Rita Segato (2016b) tem uma posição diferente de Oyěwùmí e Lugones relativamente à inexistência do gênero tanto nas sociedades africanas quanto nas ameríndias. Para ela o patriarcado e a consequente hierarquia de gênero, prestígio masculino e violências variadas são uma realidade irrefutável (e aqui temos uma disputa de narrativas sobre diferentes relatos históricos e etnográficos), mas, em acordo com um modo de desenhar o patriarcado moderno, há que se falar em um novo estado de coisas advindo do processo incessantemente colonizador do gênero. Opõe-se, assim, para Segato, um patriarcado de baixa intensidade a um patriarcado de alta intensidade: "a captura colonial del hombre no blanco y una caída abrupta del espacio doméstico en valor y en politicidad" (SEGATO, 2016b, p. 167).

O homem não branco é capturado pela masculinidade branca, uma vez que ela é a masculinidade vencedora: "Dividido por un conflicto de lealtades entre su mandato de masculinidad y su conexión com su comunidad y red de parentesco, acaba emulando dentro de casa la agresividad viril del vencedor y es él quien va a transferir la violencia apropiadora del mundo que llega hacia el interior de las relaciones de su propio mundo" (SEGATO, 2016a, p. 93).

Relativamente às comunidades indígenas, Federici (2017) aponta relatos sobre a instauração de uma "hierarquia sexual" que "privou as mulheres indígenas de sua autonomia e deu a seus familiares homens mais poder sobre elas. Sob as novas leis, as mulheres casadas tornaram-se propriedades dos homens e foram forçadas (contra o costume tradicional) a seguir seus maridos às casas deles" (FEDERICI, 2017, p. 220). Federici também descreve a existência de solidariedades mútuas entre a população branca de classe baixa vinda da Europa para colonizar a América e a população indígena e africana, bem como as inúmeras ações e atos legais necessários para a construção de uma sociedade racista: a proibição de casamentos, a escravização dos filhos advindos de relacionamento inter-raciais, e solidariedades econômicas e epistêmicas sistematicamente proibidas e criminalizadas, com mais ou menos sucesso, na América inglesa e na América ibero-espanhola, e, portanto, "provas da criação de cima para baixo de uma sociedade segregada e racista.

Mais ainda: 


\begin{abstract}
Com a institucionalização da escravatura (no caribe), que veio acompanhada por uma diminuição da carga laboral para os trabalhadores brancos e por uma queda no número de mulheres vindas da Europa como esposas para os fazendeiros, a situação mudou drasticamente. Fosse qual fosse sua origem social, as mulheres brancas ascenderam de categoria, esposadas dentro das classes mais altas do poder branco. E, quando se tornou possível, também se tornaram donas de escravos, geralmente de mulheres, empregadas para realizar o trabalho doméstico (FEDERICI, 2017, p. 216).
\end{abstract}

Assim, a compreensão de um sistema colonial de gênero advém da ideia de que seja difícil não compreender uma história europeia ditando e sendo ditada pelos rumos da colonização, mas também do fato de que uma grande parte do trabalho de reprodução em países de passado colonialista seja feita primordialmente pelas mulheres negras e de classes mais baixas. A colonialidade de gênero é, então, perpassada pela produção colonial/moderna das hierarquias raciais, e, como dirá Maria Lugones, o trabalho torna-se generificado e racializado ao mesmo tempo.

Também Segato (2016a) apontará para um processo similar ocorrendo nas comunidades indígenas do novo continente. Ela reforçará que o processo de nuclearização da família e de constituição de um espaço íntimo e privado na modernidade ensejará na existência de uma nova hierarquia de gênero e, portanto, para ela, na existência de dois espaços (público e privado) binariamente dispostos. No mundo-aldeia, o espaço público não existia como referência para o espaço privado, não havia a ideia de uma universalidade, senão instâncias com validade ontológicas plenas e intercomunicáveis, portanto duais e dotadas de importância para a comunidade, cada uma à sua maneira. Assim:

\footnotetext{
En esa atmósfera colectiva y comunitaria no hay englobamiento, no hay sujeto universal, hombre con $\mathrm{H}$ mayúscula catapultado por el humanismo colonial-moderno a la posición de Sujeto Universal, ni enunciados de valor general capaces de representar a todos. No hay tampoco un referente universal de lo que se define como humano, ni equivalente universal del valor que permita mercantilizar el hábitat o volver negociable el nicho territorial y su paisaje. Cada naturaleza es irreductible a la otra (SEGATO, 2016a, p. 93) (grifos como no original).
}

Alçar o espaço público ao lugar de referência da comunidade, dirá Segato, instaura no mundo-aldeia uma nova hierarquia binária, porque o institui como local da universalidade, e, portanto, onde a política e os assuntos maiores são tratados em "pé de igualdade" por todos aqueles que pertencem à arena pública. Essa passa a ser a referência em relação ao outro espaço, o doméstico, onde restam os assuntos menores, os concernentes às mulheres, às crianças e, obviamente, às populações racializadas, os marginalizados da divisão internacional do trabalho, bem como aqueles que não atendem à norma: "el sujeto natural de esa esfera pública, heredera del espacio político de los hombres en la comunidad, será, por marca de origen y genealogía: 
1) masculino; 2) hijo de la captura colonial y, por lo tanto, a) blanco o blanqueado; b) propietario; c) letrado; y d) pater-familias (describirlo como 'heterosexual' no es adecuado, ya que de la sexualidad propiamente dicha del patriarca sabemos muy poco)" (SEGATO, 2016a, p. 94).

O rebaixamento do espaço privado e dos assuntos relacionados às mulheres, a "feminilização" de um espaço antes dotado de politicidade, mas que precisará ser "secularizado", transfigurado, escondido ou destruído a fim de constituir a universalidade (e esconder os seus outros), a isso Segato dá o nome de "minorização". A colonialidade de gênero instala-se a partir do momento em que as hierarquias duais são esquecidas e o binarismo é compreendido como o único modo pelo qual é possível conceber a existência das relações sociais.

Ao modo como o projeto epistêmico ocidental é absorvido pelas comunidades, Segato dá o nome de crioulização ou "caciquismo fundamentalista" (2016a), a colonização do imaginário cultural e identitário enquanto essencialistas e imutáveis, algo como a contraface de uma identidade europeia, tão forjada quanto a outra. No entanto, o projeto epistêmico europeu - pretensamente universal - não demanda legitimidade para a sua existência, enquanto nós, as outras, precisaremos forjar continuamente uma identidade que lhe faça contraface ainda quando nos prejudica, como a crença de que as nossas relações de gênero sempre foram do mesmo modo como a conhecemos na colonial-modernidade.

Reforçar a importância de se discutir a colonialidade de gênero, ou seja, destituir os assuntos "menores" da esfera do privado, e compreender mais uma vez que o "pessoal é político" é apresentar os efeitos perversos da aliança entre o patriarcado e o capitalismo a fim de não compartimentalizarmos a história das mulheres como um problema guetificado, e sim como uma das facetas que ensejam a piora das condições de vida da população a nível global.

\section{Considerações Finais}

Ao proceder a uma análise das diferentes narrativas sobre a existência de um insurgente patriarcado na colonial-modernidade, o texto pautou-se na premente necessidade política de historicizar categorias caras à luta feminista radical como a categoria de gênero. Para além de provas cabais ou de disputas de narrativas, as autoras promovem o descentramento do sujeito epistêmico e político, a partir da desconfiança do humanismo universalista, mas também do sujeito do feminismo branco. 
As narrativas ora apresentadas nao deixam dúvidas sobre a existência de um Sistema Colonial de Gênero, deflagrado pelo patriarcado capitalista, instituidor de hierarquias raciais e do estressamento das hierarquias de gênero, que irão se imbricar nos atravessamentos aosquais as mulheres não-brancas passam agora a se vincular. No entanto, ainda quando possam ter um olhar para o passado mais condescendente com as supostas inexistências de violências e hierarquias de gênero, as teorizações sobre a mutabilidade das relações de gênero nas colônias, e mesmo na metrópole, apontam para o fato de que é impossível imaginarmos categorias, relações e hieraquias que fossem sempre do mesmo modo, em todo lugar e desde sempre.

O que finalmente está em jogo talvez seja exatamente isso: a necessidade de que possamos imaginar relações sociais outras, ocorrendo em outros tempos-espaços, que nos inspirem a almejar um presente e um futuro muito melhor para as mulheres e para as relações sociais como um todo; isto só é possível com o aniquilamento do sistema colonial-capitalista e das relações que o instituiu, sem as quais a racialização das populações marginalizadas, a invizibilização de sujeitas políticas outras e o roubo de imaginações emancipatórias diversas não teriam existido.

\section{REFERÊNCIAS BIBLIOGRÁFICAS}

ARRUZZA, Cinzia; BHATTACHARYA, Tithi; FRASER, Nancy. Feminismo para os 99\%: um manifesto. Tradução Heci Regina Candiani. São Paulo: Boitempo, 2019, 1. ed.

CURIEL, Ochy. La descolonización desde una propuesta feminista crítica. In_ CURIEL, Ochy ; GALINDO, María. Descolonización y Despatriarcalización de y desde los feminismos de Abya Yala. ACSUR-LAS SEGOVIAS, 2015 Associació per la cooperació amb el Sud.

DAVIS, Angela. Classe e Raça no início da campanha pelos direitos das mulheres. In: Mulheres, Raça e Classe. São Paulo: Boitempo, 2016.

FEDERICI, Silvia. Salarios contra el trabajo doméstico. In: Revolución en punto cero: trabajo doméstico, reproducción y luchas feministas. Madrid: Traficante de Sueños, 2013.

FEDERICI, Silvia. O Calibã e a Bruxa: Mulheres, Corpo e Acumulação Primitiva. São Paulo: Elefante, 2017.

FEDERICI, Silvia. Mulheres e caça às Bruxas: da Idade Média aos dias atuais. São Paulo: Boitempo, 2019.

GONZALEZ, Lélia. Por um feminismo Afro-latino-Americano. Caderno de Formação Política do Círculo Palmarino $n^{o}$ 1. Batalha de Ideias. Brasil, 2011.

HIRATA, Helena. Gênero, classe e raça Interseccionalidade e consubstancialidade das relações sociais. Tempo Social, Revista de Sociologia da USP, v. 26, n. 1, 2014. 
GROSFOGUEL, Ramón. Racismo/sexismo epistémico, universidades occidentalizadas y los cuatro genocidios/epistemicidios del largo siglo XVI. Tabula Rasa, Bogotá, 19, Jul-dez 2013, $31-58$.

LUGONES, María. Colonialidad y Género. Tabula Rasa. Bogotá - Colombia, No 9, juliodiciembre 2008, 73-101.

OYĚWÙMÍ, Oyèrónké. Conceituando o gênero: os fundamentos eurocêntricos dos conceitos feministas e o desafio das epistemologias africanas. Tradução por Juliana Araújo Lopes para uso didático de: OYĚWÙMÍ, Oyèrónké. Conceptualizing Gender: The Eurocentric Foundations of Feminist Concepts and the challenge of African Epistemologies. African Gender Scholarship: Concepts, Methodologies and Paradigms. CODESRIA Gender Series.Volume 1, Dakar, CODESRIA, 2004, p. 1-8.

OYĚWÙMÍ, Oyèrónkẹ́: A invenção das mulheres: Construindo um sentido africano para os discursos ocidentais de gênero. Tradução provisória para uso didático por wanderson flor do nascimento. Revisão de Aline Matos da Rocha. Título original: The invention of women: Making an African Sense of Western Gender Discourses Minneapolis: University of Minnesota Press, 1997.

SAFFIOTI, Iara Bongiovani Heleieth. Primórdios do conceito de gênero. Cadernos Pagu, (12), 157-163. 2015 Recuperado de https://periodicos.sbu.unicamp.br/ojs/index.php/cadpagu/article/view/8634812.

SEGATO, Rita Laura. Gênero e colonialidade: em busca de chaves de leitura e de um vocabulário estratégico descolonial. e-cadernos CES, 18, 2012: 106-131.

SEGATO, Rita Laura. Patriarcado: del borde al centro. Disciplinamiento, territorialidad y crueldad en la fase apocalíptica del capital. In _. La guerra contra las mujeres. Madrid: Traficante de Sueños, 2016a.

SEGATO, Rita Laura. Cinco debates feministas. Temas para una reflexión divergente sobre la violencia contra las mujeres. In_. La guerra contra las mujeres. Madrid: Traficante de Sueños, $2016 b$. 